Www.jmscr.igmpublication.org

Impact Factor (SJIF): 6.379

Index Copernicus Value: 79.54

ISSN (e)-2347-176x ISSN (p) 2455-0450

crossrefDOI: https://dx.doi.org/10.18535/jmscr/v6i11.143

Journal Of Medical Science And Clinical Research

IGM Publication

An Official Publication of IGM Publication

\title{
Diagnostic Evaluation of Ocular Surface Disease Index Questionnaire for Dry Eye Diseases
}

\author{
Authors \\ Anjana Nair S ${ }^{1}$, V Sahasranamam ${ }^{2 *}$, Susan Thomas ${ }^{3}$, Karthik Raj Prabhakar ${ }^{4}$ \\ ${ }^{1,2,3}$ Regional Institute of Ophthalmology, Thiruvananthapuram, Kerala, India \\ ${ }^{4}$ Government Medical College, Thiruvananthapuram, Kerala, India \\ *Corresponding Author \\ V Sahasranamam \\ Director, Regional Institute of Ophthalmology, Thiruvananthapuram-695001, India \\ Phone number: +91-9846020421, Email: drsahasranamam@gmail.com
}

\begin{abstract}
Purpose: To find out whether subjective evaluation of dry eye with OSDI questionnaire correlates with clinical tests of dry eye

Method: 111 patients between $30 \& 60$ years of age, coming to OPD of a tertiary care centre with symptoms of dry eye were taken for the study. The study subjects were made to fill up the OSDI questionnaire and the tear film of same subjects were analysed with schirmer tests \& TBUT. People who had previous ocular surgeries or having acute or chronic ocular surface abnormalities were excluded. Tools used are validated OSDI questionnaire, schirmer strips, fluorescein strips and slit lamp. Data were entered in Microsoft excel data sheets and analysed using SPSS 16.

Results: Out of 73 patients who had dry eye (low schirmer and TBUT values) 71patients (97.26\%) were having OSDI scores suggestive of dry eye. Among those 71 patients, 27 patients had severe dry eye scores (37\%), 22 had moderate scores (30.1\%) and 22 had mild scores (30.1\%). Out of 38 patients who did not have dry eye, 20 patients had OSDI scores suggestive of dry eye and among those 20; 9(23.7\%), $9(23.7 \%) \& 2(5.3 \%)$ had mild, moderate \& severe OSDI scores respectively.

Conclusion: The sensitivity of OSDI Questionnaire as per this study is $97.26 \%$ in detecting dry eye. But the specificity of test is only $47.37 \%$. The questionnaire can be used as screening tool for dry eye diseases.

Keywords: dry eye disease; tear film evaluation; OSDI Questionnaire; OSDI score.
\end{abstract}

\section{Introduction}

Dry eye disease has definitely become an emerging ophthalmological problem affecting 5 to $30 \%$ of general population ${ }^{[1],[2]}$. It affects the quality of patient's life making even the routine activities difficult. The symptoms of dry eye include mild ocular discomfort, burning sensation, foreign body sensation, blurring of vision and contact lens intolerance. In spite of its high prevalence in society and its negative impact on patient's visual function the disease is often unrecognized and under diagnosed $^{[1]}$. Here lies the importance of diagnosing the dry eye diseases. 
As of now there is no single 'gold standard' test for diagnosing dry eye disease ${ }^{[1],[3]}$. Most clinicians prefer a combination of both symptoms and clinical tests for diagnosing and treating dry eye diseases. OSDI questionnaire comprises of 12 questions, which assess the frequency of dry eye symptoms ${ }^{[1]}$. The total score ranges from 0 to 100 in which one can grade the severity of dry eye disease to normal, mild moderate and severe dry eye. OSDI questionnaire has turned out to be a good tool for diagnosing DED. This study analyses the effectiveness of OSDI questionnaire in diagnosing DED.

\section{Materials and Methods}

This is a cross sectional study conducted in a tertiary eye care centre in Kerala and all the participants were patients who attended outpatient department with symptoms of dry eye. Patients with age 30 to 60 years were included and those with acute eye infections, extensive corneal or conjunctival pathology, lid abnormality and those who have undergone eye surgery in the past were excluded. Patients with abnormal values for both schirmer tests and tear film breakup time were considered as dry eye cases and negative for both as normal. Thus we studied 73 dry eye cases and 38 non-dry eye cases (total of 111 patients).

Detailed informed consent was taken from all the patients before study. Ethical clearance was obtained before the commencement of the study. The following data were collected from the study subjects - age, sex, systemic illness and vision assessment was done. All patients underwent preliminary slit lamp examination. The study subjects were asked to fill up the OSDI questionnaire and tear film was analysed using schirmer tests and tear film breakup time. The data were entered into Microsoft excel data sheet and detailed analyses were done using Statistical Package for Social Sciences (SPSS) version 16. Positive predictive value, negative predictive value, sensitivity and specificity of the test were calculated.

\section{Results}

Out of 111 patients 93 patients were females (83.8 $\%)$ and 18 patients $(16.2 \%)$ were males

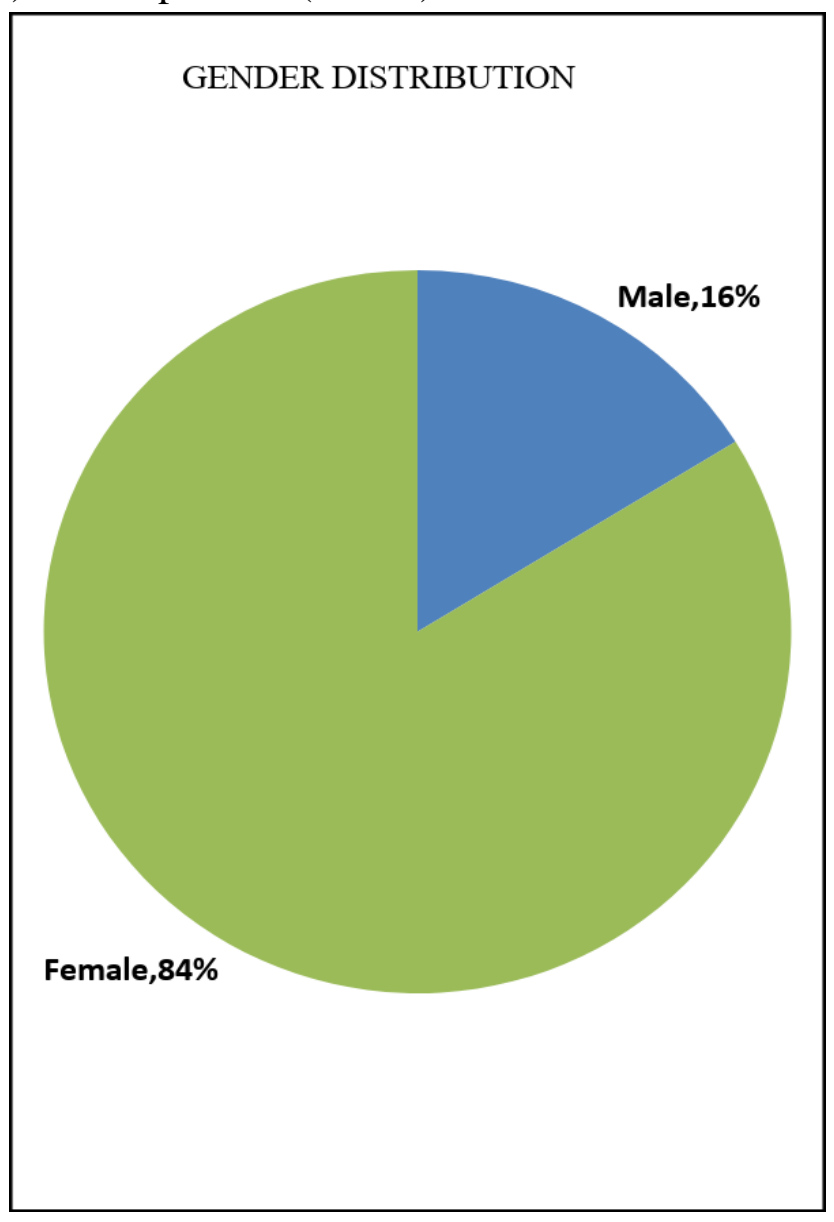

Fig 1: Gender distribution of study population

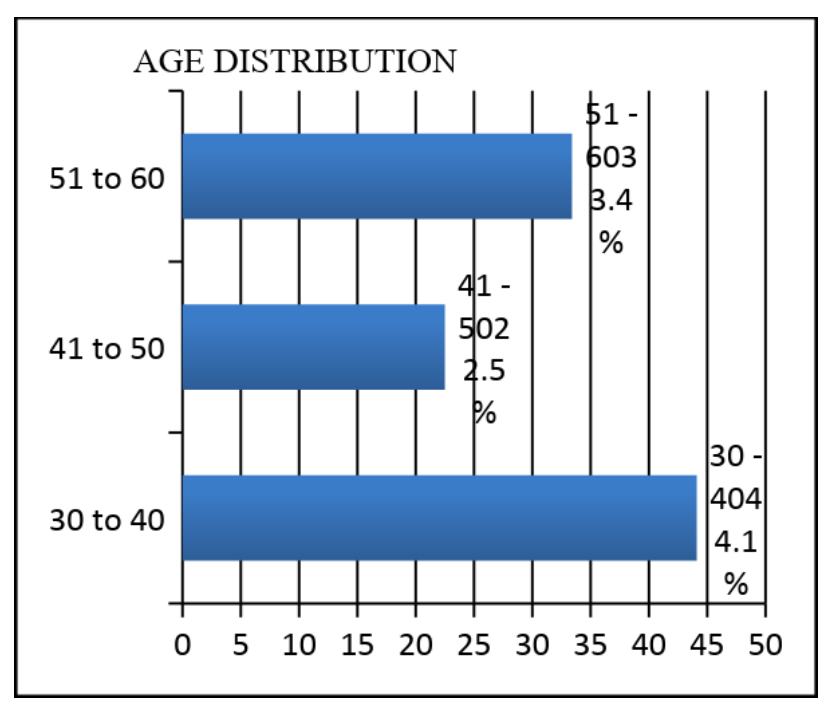

Fig 2: Age group distribution

$44.1 \%$ of patients who participated in our study belonged to the age group of 30 to 40 years, $22.5 \%$ belonged to 41 to 50 years of age and the rest were in 50 to 60 years of age. 


\section{JMSCR Vol||06||Issue||11||Page 814-818||November}

The most common symptom for which these patients sought medical care was persistent foreign body sensation. Other significant symptom was itching.

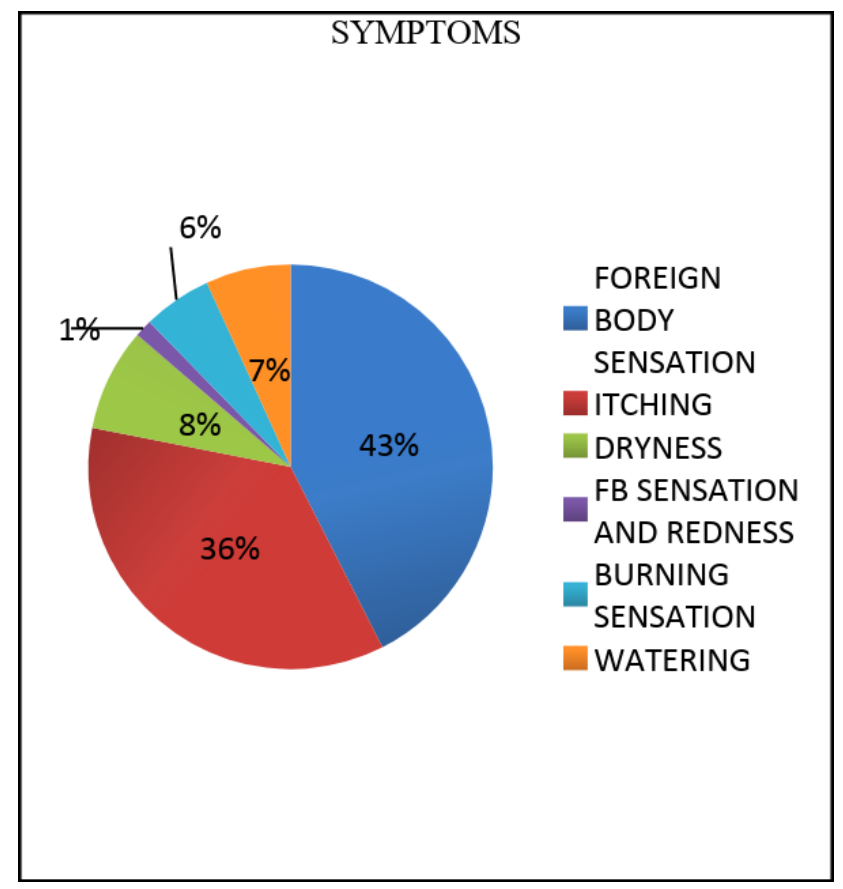

Fig 3: Commonest symptom of presentation

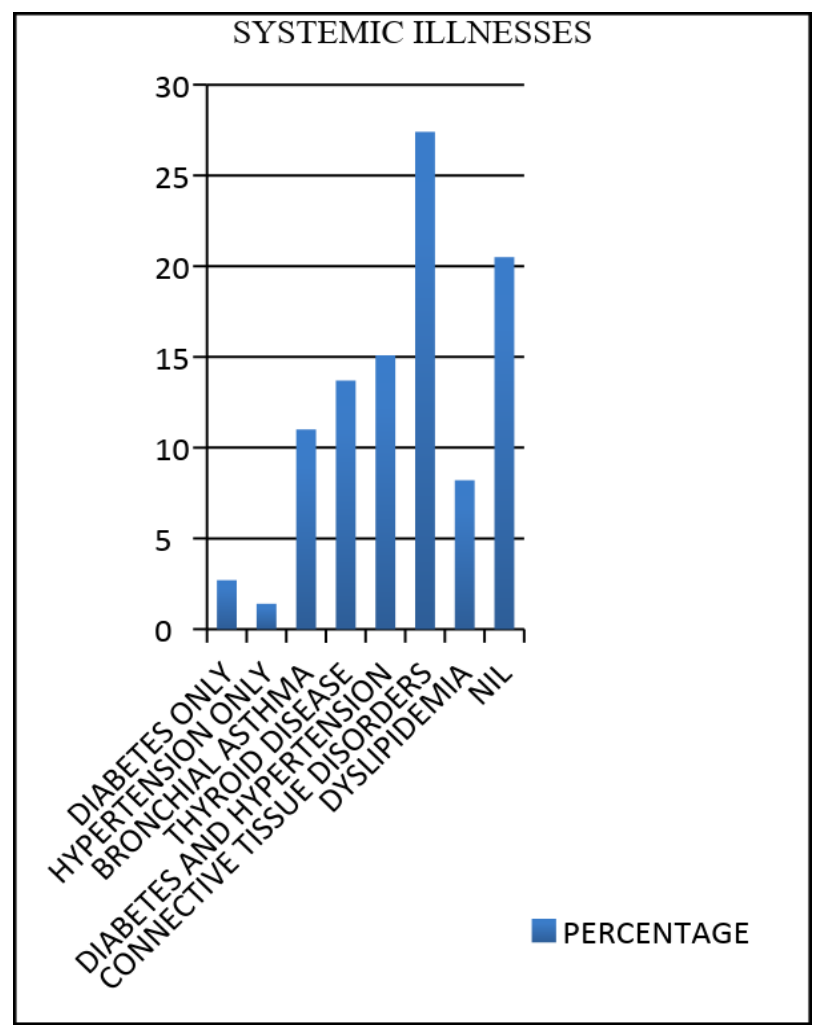

Fig 4: Distribution of systemic illness among patients with dry eye in the study population
Among the dry eye patients $64 \%$ had associated systemic illnesses of which connective tissue disease was the commonest (27.4\%).

Out of 111 patients 73 were having dry eye, which was concluded after getting low schirmer and TBUT values. Among them 71 patients had OSDI scores suggestive of dry eye. Likewise 38 patients who showed high schirmer and TBUT values (non dry eye group) 18 patients showed OSDI scores which excluded dry eye and 20 patients had values suggestive of dry eyes.

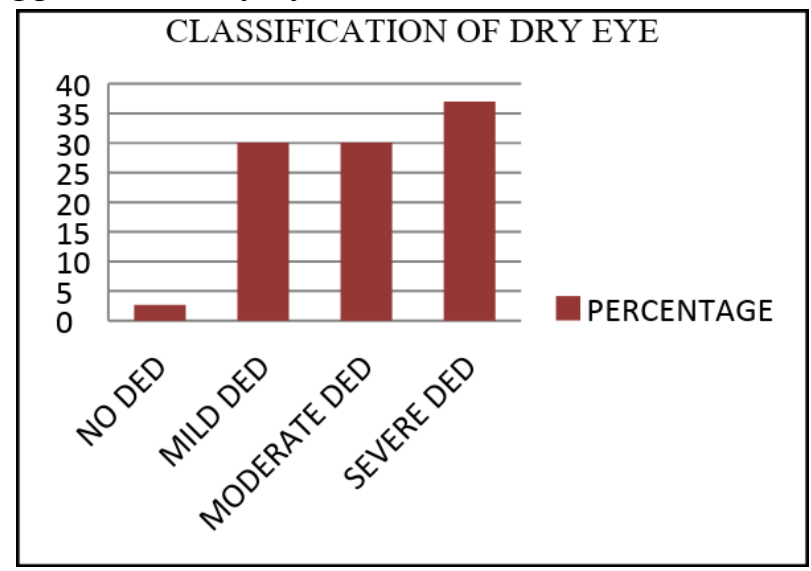

Fig 5: Classification of dry eye symptoms according to OSDI score in patients with dry eye

\begin{tabular}{|l|c|c|}
\hline & DRY EYE & NO DRY EYE \\
\hline $\begin{array}{l}\text { OSDI (suggestive } \\
\text { of DED) }\end{array}$ & 71 & 20 \\
\hline $\begin{array}{l}\text { OSDI (not } \\
\text { suggestive of DED) }\end{array}$ & 2 & 18 \\
\hline TOTAL & 73 & 38 \\
\hline
\end{tabular}

Sensitivity of the test is $97.26 \%$

Specificity of the test is $47.37 \%$.

Positive predictive value of OSDI questionnaire is $78.02 \%$

Negative predictive value is $90 \%$.

Positive likelihood ratio is 1.8

Negative likelihood ratio is 0.06

\section{Discussion}

Our study population were female predominant (83.4\%), which is in accordance with other peerreviewed literature ${ }^{[5]-[7]}$. Prevalence of dry eye syndrome is two to three times more in females when compared to males. This disparity among genders is best explained by differential hormonal 
actions. Testosterone has a protective action on lacrimal glands, whilst estrogen is detrimental. The mean age of patients with dry eye who participated in our study was 43.12 years with largest number of patients belonging to 30 to 40 years of age. But most of the studies show slightly higher mean age of participants ${ }^{[8]}$. A study by Cathy Mcathy showed a mean age of 59.2 years $^{[9]}$. The most common single systemic disease associated with dry eye disease was connective tissue disorders including autoimmune diseases. Thyroid diseases also constituted a significant proportion of systemic illnesses in our study. A study by Ji Min Ahl et al reports thyroid diseases as significant risk factor ${ }^{[7]}$. Another study by Ismailova et al reported $65 \%$ patients with TED had dry eyes ${ }^{[10]}$. There were even studies which described higher OSDI scores in thyroid patients ${ }^{[11]-[12]}$. Other systemic diseases associated with the dry eye symptoms were diabetes, hypertension and dyslipidaemia and similarly the study by Erder et al also says dry eyes can be associated with metabolic syndrome ${ }^{[13]-[15]}$.

The sensitivity of the questionnaire was found to be $97.2 \%$ by this study, but the specificity is $47.37 \%$. Accordingly, from our study it can be safely concluded that OSDI questionnaire can very well be used for screening dry eye diseases. Study by Asiedu et al also gave substance to the same and furthermore corroborated by many other studies ${ }^{[16]-}$ ${ }^{[18]}$. The ease with which patients can respond to this questionnaire makes it more useful and relevant. Hence situations wherein ophthalmic surgeons are in short supply, even ophthalmologically untrained health care providers can screen for DED in patients at risk.

\section{Conclusion}

Dry eye diseases is one of the most frequently encountered ocular morbidity in ophthalmic practices. OSDI is a reliable tool for screening patients having dry eye. OSDI is an inimitable instrument to assess both the frequency of symptoms as well as visual functioning.

\section{References}

1. Lin H, Yiu SC. Dry eye disease: A review of diagnostic approaches and treatments. Saudi J Ophthalmol. 2014 Jul;28(3):173-81.

2. Amparo F, Schaumberg DA, Dana R. Comparison of Two Questionnaires for Dry Eye Symptom Assessment: The Ocular Surface Disease Index and the Symptom Assessment in Dry Eye. Ophthalmology. 2015 Jul;122(7):1498-503.

3. Guo Y, Peng R, Feng K, Hong J. Diagnostic Performance of McMonnies Questionnaire as a Screening Survey for Dry Eye: A Multicenter Analysis [Internet]. Journal of Ophthalmology. 2016

4. Milner MS, Beckman KA, Luchs JI, Allen QB, Awdeh RM, Berdahl J, et al. Dysfunctional tear syndrome: dry eye disease and associated tear film disorders - new strategies for diagnosis and treatment. Curr Opin Ophthalmol. 2017 Jan;28(Suppl 1):347.

5. Valim V, Trevisani VFM, Sousa JM de, Vilela VS, Belfort R. Current Approach to Dry Eye Disease. Clin Rev Allergy Immunol. 2015 Dec 1;49(3):288-97.

6. Nebbioso M, Del Regno P, Gharbiya M, Sacchetti M, Plateroti R, Lambiase A. Analysis of the Pathogenic Factors and Management of Dry Eye in Ocular Surface Disorders. Int J Mol Sci. 2017 Aug 13;18(8):1764.

7. Ahn JM, Lee SH, Rim THT, Park RJ, Yang HS, Kim T im, et al. Prevalence of and Risk Factors Associated With Dry Eye: The Korea National Health and Nutrition Examination Survey 2010-2011. Am J Ophthalmol. 2014 Dec 1;158(6):1205-1214.e7.

8. Peck T, Olsakovsky L, Aggarwal S. Dry Eye Syndrome in Menopause and Perimenopausal Age Group. J -Life Health. 2017;8(2):51-4.

9. Lin P-Y, Tsai S-Y, Cheng C-Y, Liu J-H, Chou P, Hsu W-M. Prevalence of dry eye among an elderly Chinese population in 
Taiwan. Ophthalmology. 2003 Jun 1;110(6):1096-101.

10. Ismailova DS, Fedorov AA, Grusha YO. Ocular Surface Changes in Thyroid Eye Disease. Orbit. 2013 Apr 1;32(2):87-90.

11. Bruscolini A, Abbouda A, Locuratolo N, Restivo L, Trimboli P, Romanelli F. Dry Eye Syndrome in Non-Exophthalmic Graves' Disease. Semin Ophthalmol. 2015 Nov 2;30(5-6):372-6.

12. Koca G, Acar U, Atilgan HI, Acar DE, Altiparmak UE, Demirel K, et al. Changes in conjunctival cytology and tear function tests with radioiodine treatment for hyperthyroidism. Ann Nucl Med. 2013 Oct 1;27(8):694-9.

13. Zhang X, Zhao L, Deng S, Sun X, Wang N. Dry Eye Syndrome in Patients with Diabetes Mellitus: Prevalence, Etiology, and Clinical Characteristics [Internet].

14. DeMill DL, Hussain M, Pop-Busui R, Shtein RM. Ocular Surface Disease in Patients with Diabetic Peripheral Neuropathy. $\mathrm{Br} \quad \mathrm{J}$ Ophthalmol. 2016 Jul;100(7):924-8.

15. Erdur SK, Aydin R, Ozsutcu M, Olmuscelik $\mathrm{O}$, Eliacik $\mathrm{M}$, Demirci $\mathrm{G}$, et al. The Relationship between Metabolic Syndrome, Its Components, and Dry Eye: A Cross-Sectional Study. Curr Eye Res. 2017 Aug 3;42(8):11157.

16. Li W, Graham AD, Lin MC. Understanding Ocular Discomfort and Dryness Using the Pain Sensitivity Questionnaire. PloS One. 2016;11(5):e0154753.

17. Alves M, Reinach PS, Paula JS, Cruz AAV e, Bachette L, Faustino J, et al. Comparison of Diagnostic Tests in Distinct Well-Defined Conditions Related to Dry Eye Disease. PLOS ONE. 2014 May 21;9(5):e97921.

18. Asiedu K, Kyei S, Mensah SN, Ocansey S, Abu LS, Kyere EA. Ocular Surface Disease Index (osdi) Versus the Standard Patient Evaluation of Eye Dryness (speed): A Study of a Nonclinical Sample. Cornea. 2016 Feb 1;35(2):175-80. 